\title{
Sleep Disorders: Do Patients Follow up as Advised?
}

\author{
Nileena NK Mana ${ }^{1}$, Lakshmi Ranganathan², Hema Deenadayalan ${ }^{3}$, Nagarajan Ramakrishnan ${ }^{4}$
}

\begin{abstract}
The loss to follow-up is a common issue in chronic disease management and can have a significant impact on the outcome. This study is an attempt to monitor the proportion of patients who come for a follow-up visit within the prescribed time in a sleep clinic. A total of 204 patients (mean age-46 years) were included in the study (147 (72.1\%) males and 57 (13.7\%) females), of which, 192 patients were recommended a follow-up visit by the sleep physician. Of the 192, 27 patients (14\%) came for the follow-up. The follow-up rate was the highest in patients with insomnia and sleep disorders secondary to psychiatric conditions and the lowest in patients with sleep-disordered breathing and miscellaneous sleep disorders. The dismal rate of follow-up reflects the necessity of increasing awareness about the importance of treating sleep disorders in the general population.

Keywords: Awareness, Follow-up, Sleep disorders.

Indian Journal of Sleep Medicine (2019): 10.5005/jp-journals-10069-0036
\end{abstract}

\section{INTRODUCTION}

Clinical follow-up is indispensable in the treatment of chronic diseases. After the diagnosis is established and treatment is started, the patient is required to present for the follow-up to assess the response and compliance to treatment, and address adverse effects or complications, if any. The duration of follow-up depends on the chronicity and nature of the disease in question.

Many studies have been carried out to look into reasons for dropout rates and their prognostic consequences. Reasons for loss to follow-up, in an Indian scenario, include financial or travel difficulties, concern regarding the adverse effects, misconceptions concerning the disease, preference for alternative medicine, etc. ${ }^{1}$ The loss to follow-up rates has also been shown to vary depending on the classification of the diagnosis.

The branch of sleep medicine is relatively new in the Indian medical domain ${ }^{2}$ and awareness of sleep disorders among both the medical personnel and the general population is less than desired. In addition to the lack of awareness, access to sleep specialists is also limited in most parts of the country even in urban areas. This may deter patients from availing treatment and further impede follow-up visits.

This study is an attempt to assess the proportion of patients who come for follow-up after the initial diagnosis and commencement of treatment in a sleep clinic.

\section{Materials and Methods}

This is a retrospective study conducted in a free-standing sleep clinic in Chennai, India. All new patients who presented to the clinic from January to March 2018 were included.

Patients underwent a comprehensive assessment by the sleep physician and treatment initiated as per the diagnosis. Patients were usually asked to present for a follow-up visit, as deemed appropriate by the sleep physician. The usual follow-up period suggested by the physician was 1 month. Some of the patients were asked to follow up in 1-3 months if they were residing outside Chennai or could not make the follow-up by 1 month on account of any other personal reason. The participants were defined to be nonadherent to the follow-up instruction if they fail to come for the follow-up within 2 weeks of the recommended follow-up date. The main diagnoses

\footnotetext{
$\overline{{ }^{1-4} \text { Nithra Institute of Sleep Sciences, Annanagar, Chennai, Tamil Nadu, }}$ India

Corresponding Author: Nagarajan Ramakrishnan, Nithra Institute of Sleep Sciences, Annanagar, Chennai, Tamil Nadu, India, e-mail: ram@ nithra.com

How to cite this article: Mana NNK, Ranganathan L, et al. Sleep Disorders: Do Patients Follow up as Advised? Indian Sleep Med 2019;14(2):29-31.

Source of support: Nil

Conflict of interest: None
}

considered in this study were sleep-disordered breathing, insomnia, circadian rhythm disorders, sleep issues secondary to psychiatric conditions, and miscellaneous sleep disorders that include restless leg syndrome, bruxism, nocturnal seizures, poor sleep hygiene, etc.

\section{Data Collection}

Demographic details such as patients' age, gender, place of residence, and referral details were noted. Patients' main diagnosis, treatment plan, and the subsequent follow-up period as suggested by the sleep physician were noted from their medical records.

The data were analyzed after 3 months, to evaluate the percentage of patients who had adhered to the doctor's instructions for clinical follow-up. Patients whose follow-up was scheduled for a period later than 3 months were excluded from the analysis.

\section{Statistical Analysis}

Descriptive characteristics of the patients like age, gender, and diagnosis were analyzed and frequencies were tabulated. Patients were categorized based on their prescribed follow-up period. The proportion of patients who presented for the follow-up was calculated and further categorized based on the diagnosis. Demographic characteristics of patients who presented for follow-up and those who did not were compared.

\section{RESULTS}

A total of 204 patients (mean age $-46.4 \pm 15.4$ years) were included in the study, of which, 147 (72.1\%) were males and 57 (13.7\%) were 
Sleep Disorders: Do Patients Follow up as Advised?

Table 1: Patient demographics and diagnosis

\begin{tabular}{lll}
\hline Patient characteristics & Number & Percentage \\
\hline Total number of patients & 204 & \\
Age & $46.4 \pm 15.4$ & \\
Males & 147 & 72.1 \\
$\begin{array}{l}\text { Females } \\
\text { Diagnosis }\end{array}$ & 57 & 27.9 \\
$\quad \begin{array}{l}\text { Sleep-disordered breathing } \\
\text { Insomnia }\end{array}$ & 141 & 69.1 \\
$\quad \begin{array}{l}\text { Sleep disorders secondary to } \\
\text { psychiatric conditions }\end{array}$ & 28 & 13.7 \\
$\quad \begin{array}{l}\text { Circadian rhythm disorders } \\
\quad \text { Others }\end{array}$ & 6 & 11.8 \\
$\begin{array}{l}\text { Follow-up } \\
\quad \begin{array}{l}\text { Follow-up suggested by } \\
\text { physician }\end{array}\end{array}$ & 5 & 2.9 \\
$\quad \begin{array}{l}\text { Follow-up if required } \\
\text { Follow-up not suggested by } \\
\text { physician }\end{array}$ & 192 & 2.5 \\
\hline
\end{tabular}

Table 2: Follow-up pattern for common sleep disorders

\begin{tabular}{llc}
\hline & $\begin{array}{l}\text { Number of patients } \\
\text { who presented for } \\
\text { follow-up }\end{array}$ & \\
Diagnosis & 11 & 8.1 \\
\hline Sleep disordered breathing & 8 & 30.8 \\
Insomnia & 7 & 31.8 \\
Sleep disorders secondary & & \\
to psychiatric conditions & 1 & 16.7 \\
Circadian rhythm disorders & 1 & \\
\hline
\end{tabular}

"Percentage was computed with number of patients with a specific diagnosis who came for follow-up against the total number of patients with the same diagnosis who were scheduled for a follow-up visit

females. Of the 204 patients, 192 (94.1\%) were asked to come for a follow-up visit, 10 (4.9\%) patients were asked to come if they considered it necessary (si opius sit-SOS), and 2 (1.0\%) were not required to follow-up (Table 1 ).

The patients who were asked to come for follow-up SOS consisted of five patients with sleep-disordered breathing, two patients with insomnia, one with sleep disorder secondary to psychiatric conditions, and two in the miscellaneous diagnosis category. The patients who were not required to follow-up included a case of poor sleep hygiene and a pediatric case of obstructive sleep apnea (OSA) who did not require intervention and was advised to follow up with a pediatrician.

Out of the 192 patients, who were scheduled for a follow-up visit, $27(14.1 \%)$ had presented to the clinic for follow-up within the prescribed time. Categorization based on diagnoses for the patients who had come for follow-up is presented in Table 2.

Patients who presented for follow-up were older, females, not working, self-referred, and located in the same city or state as that of the clinic (Chennai, Tamil Nadu). Clinically, those who had associated illnesses, in addition to their sleep problem (70.4\%), came for a follow-up than those who did not (46.1\%). It was observed that patients with insomnia and sleep disorders secondary to psychiatric conditions were more likely to present for follow-up (Table 3).
Table 3: Comparison of patients who presented for follow-up and who did not

\begin{tabular}{|c|c|c|}
\hline Patients characteristics & Follow-up & No follow-up \\
\hline Number of patients & 27 & 165 \\
\hline Age & $52.8 \pm 15.3$ & $46.2 \pm 14.8$ \\
\hline \multicolumn{3}{|l|}{ Gender } \\
\hline Males & 14 (51.9\%) & $125(75.8 \%)$ \\
\hline Females & $13(48.1 \%)$ & $40(24.2 \%)$ \\
\hline \multicolumn{3}{|l|}{ Occupation } \\
\hline Working & 15 (55.6\%) & $120(72.7 \%)$ \\
\hline Not working & $9(33.3 \%)$ & $30(18.2 \%)$ \\
\hline Retired/student & $3(11.1 \%)$ & $15(9.1 \%)$ \\
\hline \multicolumn{3}{|l|}{ Referral status } \\
\hline Referred by a doctor & $10(37.0 \%)$ & 79 (47.9\%) \\
\hline Self-referred & $17(63.0 \%)$ & $86(52.1 \%)$ \\
\hline \multicolumn{3}{|l|}{ Presence of associated illness } \\
\hline Yes & 19 (70.4\%) & $76(46.1 \%)$ \\
\hline No & $8(29.6 \%)$ & 89 (53.9\%) \\
\hline \multicolumn{3}{|l|}{ Place of residence } \\
\hline Chennai & 19 (70.4\%) & $106(64.2 \%)$ \\
\hline Tamil Nadu (outside Chennai) & $7(25.9 \%$ & $14(8.5 \%)$ \\
\hline Other state & $1(3.7 \%)$ & $39(23.6 \%)$ \\
\hline Other country & $0(0.0 \%)$ & $6(3.6 \%)$ \\
\hline \multicolumn{3}{|l|}{ Diagnosis } \\
\hline Sleep-disordered breathing & $11(40.7 \%)$ & $125(75.8 \%)$ \\
\hline Insomnia & $8(29.6 \%)$ & $18(10.9 \%)$ \\
\hline $\begin{array}{l}\text { Sleep-disorders secondary to } \\
\text { psychiatric conditions }\end{array}$ & $7(25.9 \%)$ & $15(9.1 \%)$ \\
\hline Circadian rhythm disorders & $1(3.7 \%)$ & $5(3.0 \%)$ \\
\hline Others & $0(0.0 \%)$ & $2(1.2 \%)$ \\
\hline
\end{tabular}

\section{Discussion}

In this study, we have attempted to assess the compliance to the physician's instructions for follow-up for sleep disorders. The study is first of its kind in an Indian scenario. In our study, almost $86 \%$ of patients had failed to present for follow-up, despite the fact that the physician explained the medical condition, treatment protocol, and possible consequences of not getting treated appropriately.

Studies have shown that common factors affecting treatment compliance are lack of awareness, misconceptions regarding healthcare, attitudes toward medication, and financial status. ${ }^{3-6}$ These factors could have played a role in deterring our patients too, to follow-up their treatment. A meta-analysis done on patients' adherence rates and follow-up pattern in several medical fields revealed that treatment adherence was seen least in sleep disorders. ${ }^{7}$

Studies which have explored the role of gender in determining the loss to follow-up have produced mixed results. ${ }^{4}$ In our study, though the patients who attended the clinic initially were mostly men, the majority of patients who came for follow-up were women. This may also be attributed to the difference in diagnosis as sleepdisordered breathing was the most common diagnosis in men while insomnia or sleep disorders secondary to psychiatric conditions were the predominant diagnoses in women.

When looking at each diagnosis, there is a major variation in the follow-up pattern. The follow-up rate was the highest in insomnia. Though sleep-disordered breathing was the most common diagnosis, only $8.1 \%$ of the patients had come for the follow-up visit. This fact 
could be representing the misconceptions and attitudes toward sleep-disordered breathing which could lead to adverse health outcomes. ${ }^{8,9}$ Moreover, those on treatment for sleep-disordered breathing often mentioned that they "felt better and did not have any problems" and did not appreciate the need for a routine follow-up. On the contrary, patients with insomnia showed better compliance reflecting the attitude toward the medications used in treating insomnia. With each follow-up, they were hoping to be weaned of medications which are often deemed to be "addictive." Gender differences in follow up may also be contributing to the compliance as females were better than males. Insomnia being the more common diagnosis in females and sleep-disordered breathing being more common in the male gender may further explain the compliance rates for follow up being higher among those with insomnia.

Though this study is first of its kind, it is not devoid of limitations. The study is retrospective and the sample size is small and the follow-up was assessed for a short duration. We had not looked into the possibility of any of the variable being a possible predictor for the follow-up pattern. This is a pilot study and we intend pursuing a prospective study over a longer duration and also addressing the reasons for not following up as advised.

This study reflects the need for creating more awareness about sleep disorders among the general population through several measures such as

- Educational efforts from sleep physician through visual, print, and social media.

- Psychoeducational sessions during consultation visits on the importance of compliance, follow up, and strict adherence to medical management.

- Providing reminders via phone calls, short-text message services, or e-mails for follow up.

- Providing options for telemedicine to negate the geographical barriers.

The awareness programs could also focus on increasing the recognition of sleep disorders among the medical personnel, which currently is inadequate based on published reports. ${ }^{10-12}$

\section{Conclusion}

The observed pattern in follow-up seen in our study suggests that current follow-up rates in a sleep clinic are suboptimal.
Comprehensive awareness programs aiming both the healthcare professionals and the general population and increasing the availability of sleep specialists will improve the current scenario and help in the better clinical management of sleep disorders.

\section{References}

1. Jennens $H$, Ramasamy R, et al. Reasons for default from treatment of chronic illnesses in a primary healthcare program in rural Tamil Nadu. Indian J Public Health 2013;57(3):173. DOI: 10.4103/0019-557X.119821.

2. Kumar S. Sleep medicine: Evolution in India. Ann Indian Acad Neurol 2013 Apr;16(2):144-145.

3. Mainbourg EMT, Belchior ADS, et al. Loss to follow-up in tuberculosis treatment and its relationship with patients' knowledge of the disease and other associated factors. Rev Salud Pública 2017 Feb 1;18(5):714. DOI: 10.15446/rsap.v18n5.54842.

4. Pagès-Puigdemont $N$, Mangues $M A$, et al. Patients' Perspective of Medication Adherence in Chronic Conditions: a Qualitative Study. Adv Ther 2016 Oct;33(10):1740-1754. DOI: 10.1007/s12325-016-0394-6.

5. Bruwer B, Sorsdahl K, et al. Barriers to Mental Health Care and Predictors of Treatment Dropout in the South African Stress and Health Study. Psychiatr Serv 2011 Jul;62(7):774-781. DOI: 10.1176/ ps.62.7.pss6207_0774.

6. Reneses B, Muñoz E, et al. Factors predicting drop-out in community mental health centres. World Psychiatry 2009 Oct;8(3):173-177. DOI: 10.1002/j.2051-5545.2009.tb00246.x.

7. DiMatteo MR. Variations in patients' adherence to medical recommendations: a quantitative review of 50 years of research. Med Care 2004 Mar;42(3):200-209. DOI: 10.1097/01.mlr.0000114908. 90348.f9.

8. Sia $\mathrm{C}-\mathrm{H}$, Hong $\mathrm{Y}$, et al. Awareness and knowledge of obstructive sleep apnea among the general population. Sleep Med 2017 Aug;36:10-17. DOI: 10.1016/j.sleep.2017.03.030.

9. Shaw R, McKenzie $S$, et al. Beliefs and attitudes toward obstructive sleep apnea evaluation and treatment among blacks. J Natl Med Assoc 2012;104(11-12):510-519. DOI: 10.1016/S0027-9684(15)30217-0.

10. Meshram SH, Meshram C, et al. Behavior, attitude, and knowledge of sleep medicine among resident doctors in university hospitals of Central India: a questionnaire based study. Chest 2007 Oct 1 132(4):652C. DOI: 10.1378/chest.132.4_MeetingAbstracts.652c.

11. Sivagnanam $G$, Thirumalaikolundusubramanian $P$, et al. Study of the knowledge, beliefs, and practice of sleep among medical undergraduates of Tamil Nadu, India. MedGenMed 2004 Oct 12;6(4):5.

12. Ramakrishnan N, Ranganathan L, et al. Sleep Medicine in India: Are Patients Better Informed Than Referral Physicians? Chest 2012 Oct 1;142(4):1069A. DOI: 10.1378/chest.1371241. 